\title{
Fteknokultura
}

\#VARelA, J. (2016). El luminoso homenaje de Goya a las mujeres, Revista Teknokultura Vol. 13(1), 321-325.

Recibido: 09-02-2016

Aceptado: 27-03-2016
Open peer review

http://revistas.ucm.es/index.php/TEKN/pages/view/opr-51853

\section{El luminoso homenaje de Goya a las mujeres}

\author{
Goya's luminous tribute to women
}

\author{
Julia Varela \\ Universidad Complutense de Madrid \\ jvarela@fis.ucm.es
}

\section{RESUMEN}

En los frescos que pintó Goya en la ermita de San Antonio de la Florida el artista aragonés no sólo creó nuevos mundos expresivos, sino que, enfrentándose a los cánones misóginos de la iglesia católica, rindió un homenaje a las mujeres que todavía en la actualidad sigue impresionándonos.

\section{Palabras Clave}

ángelas; Ermita de San Antonio de la Florida; frescos; Lumière; mujeres libres. 


\section{Abstract}

In the frescos painted by Goya in San Antonio de la Florida Chapple, the Aragonese artist not only created new expressive worlds, but, facing misogynistic canons of the Catholic Church, paid tribute to women in a way that is still impressive today.

\section{KeYWORDS}

Women angels; San Antonio de la Florida Chapple; frescos (wall paintings); Lumière; free women. 
La Ermita de San Antonio de la Florida es para Goya, en Madrid, el equivalente de lo que es para Miguel Ángel la Capilla Sixtina en Roma. He visitado recientemente la ermita con amigos extranjeros, y he disfrutado una vez más de su envolvente belleza, de la fuerza y la luz que irradian unas pinturas tan expresivas, tan dinámicas y atrevidas, en suma, tan modernas. Si contemplamos el conjunto desde la puerta principal (en la actualidad se entra por una puerta lateral, la puerta de la sacristía), y avanzamos lentamente hacia el altar, nos damos cuenta de que Goya descubrió el cine cien años antes que los hermanos Lumière, pues el espectador se siente transportado por personajes festivos que asisten en directo y asombrados a la realización de un milagro. De especial valor me parece el homenaje que el pintor aragonés rindió con sus frescos a las mujeres, convertidas en ángelas. Más que mujeres de la corte celestial parecen mujeres que acaban de salir de un corral de comedias.

Según las crónicas fue María Luisa de Parma, la esposa de Carlos IV, quien le pidió al rey que comprase para recreo de la Corte el Palacio de la Florida, una finca que estaba en las afueras de la ciudad, cerca del Parque del Oeste y del río Manzanares. En esta finca había una ermita que había diseñado Sabatini que fue destruida para levantar las caballerizas del palacio. Pero Carlos IV pidió a Filippo Fontana, otro arquitecto italiano que había trabajado con Sabatini, que diseñase una nueva ermita destinada a ser capilla real del Palacio de la Florida que se comenzó a construir hacia 1792, y se terminó en 1799. Se levantó así la que luego se llamaría la Ermita de San Antonio de la Florida, un edificio neoclásico, de cruz griega, con una cúpula interior apoyada sobre pechinas. Esta ermita se convirtió en parroquia en 1881, lo que dio lugar a que el humo de los cirios, y la aglomeración de los fieles, deteriorasen los frescos que Goya había pintado en su interior. De ahí que, para preservarlos, se construyese posteriormente, justo al lado, otra capilla similar dedicada al culto.

La ermita de San Antonio de la Florida está ligada no solo a la Corte, sino también a la acción de intelectuales y artistas. En primer lugar, fue uno de los más relevantes ilustrados, el asturiano Gaspar Melchor de Jovellanos, del que Goya había realizado un precioso retrato hacia 1798, quien le encargó que pintase los frescos que hoy forman este sorprendente conjunto. Pero además fue gracias a la mediación de intelectuales y artistas, que viendo cómo se deterioraba el tesoro artístico de la capilla, hicieron que se convirtiese en monumento nacional, a cargo del Estado, en 1905. 
Figura 1: EJEMPLOS DE LOS FRESCOS DE MUJERES DE GOYA
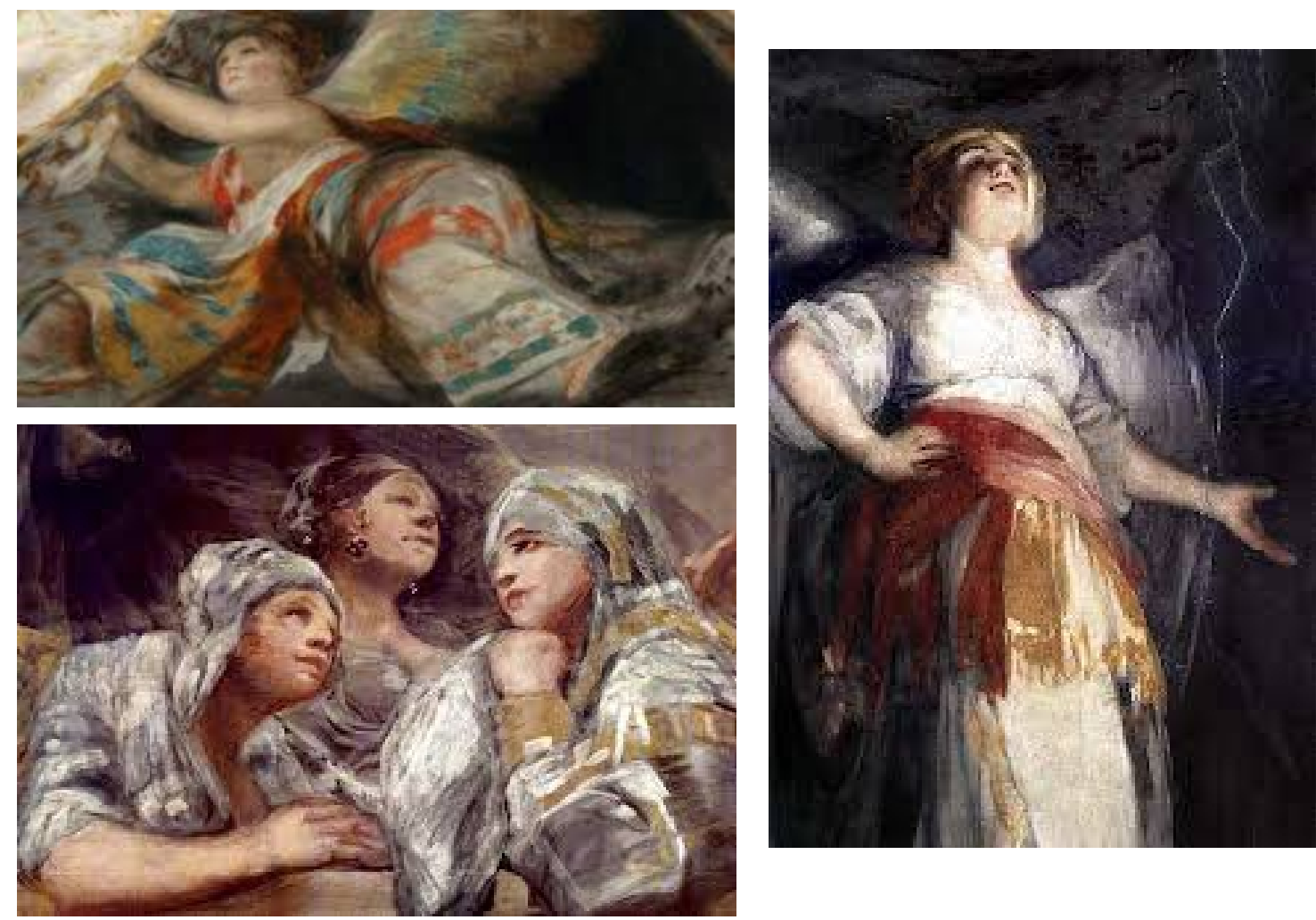

Fuente: Ermita San Antonio de la Florida. Madrid.

Goya no solo innovó técnicamente en los frescos de San Antonio de la Florida, sino que también desde el punto de vista teológico, rompió con el parecer de los asesores eclesiásticos, y se atrevió a pintar en la cúpula, un lugar hasta entonces reservado en exclusiva para la representación de la divinidad, el milagro de San Antonio resucitando a un muerto. La humanidad pasaba a ocupar el lugar preservado para lo sagrado. En torno al santo, en torno a una barandilla giratoria por la que saltan pícaros, se mueven personajes populares, y en los laterales, angelotes mofletudos descorren las cortinas para que se haga visible el prodigio. Cuando nos volvemos hacia las pechinas y a la cornisa, no solo encontramos angelotes que arrastran cortinajes, sino también multitud de ángelas desenfadadas que contribuyen así a 
que continúe el efecto teatral. Las ángelas son mujeres de gran belleza, adoptan posturas diversas, y van vestidas con ricos ropajes en los que se mezclan los colores vivos con las transparencias produciendo efectos que nos embelesan y que hacen que nos preguntemos cómo Goya se atrevió a plasmar esta historia en una época en la que la Santa Inquisición aún no había sido abolida. Algunos creen descubrir entre estas chulapas a la duquesa de Alba, y a actrices famosas de la época, como La Tirana, así como a una amante de Goya, y sin duda tanto entre los personajes del milagro como entre las ángelas habrá conocidas y conocidos del pintor que le sirvieron de modelo. Otros señalan que las ángelas son un homenaje de Goya a las muchachas de Madrid, y sobre todo a las modistillas de las clases populares que iban a la ermita el día 13 de junio en romería para pedir un novio al santo. En todo caso el pueblo es el principal personaje de la representación. El dinamismo y la belleza de las pinturas hacen que no se puedan dejar de mirar las figuras en las que el tratamiento del color y la luz nos acercan ya al expresionismo moderno.

Maruja Mallo, la rebelde artista gallega, que tras la Guerra Civil vivió en el exilio, entendió bien el homenaje que Goya rinde a las mujeres cuando en uno de sus cuadros titulado precisamente La verbena, que data de 1927, se representó a si misma, junto con su amiga la poetisa Concha Méndez, en una de las verbenas madrileñas, y las dos con alas. Las dos ángelas representan sin duda, en este caso, a dos jóvenes, vitales, independientes y seguras de sí mismas, caminando por la vida, pero este cuadro es también un homenaje al Goya de las mujeres libres.

El día 8 marzo ha sido acordado como el día internacional de las mujeres. No sería mala idea inventar como tradición que tanto las madrileñas y madrileños como los que se encuentren en Madrid en esa fecha se animen a visitar esta iglesita y disfruten de los frescos de Goya. Y si lo desean podrían de paso depositar una rosa roja en la tumba del pintor que se encuentra en el interior de la ermita.

Es lamentable que el ayuntamiento de Madrid, no haga prácticamente nada para dar a conocer una de las obras de arte más bellas del pintor aragonés. En la ermita no hay postales, solo existe un caro catálogo ya viejo, y algunas diapositivas que han perdido calidad. No estaría nada mal que este monumento volviese a depender del Estado, y que éste velase por su conservación y promoción, pues se ha convertido ya por méritos propios en patrimonio de la humanidad. 